\section{RMD Open}

Rheumatic \&

Musculoskeletal Diseases

\title{
Risk of psoriatic arthritis depending on age: analysis of data from 65 million people on statutory insurance in Germany
}

\author{
Madeline Deike, ${ }^{1}$ Ralph Brinks, ${ }^{1}$ Stephan Meller, ${ }^{2}$ Matthias Schneider, ${ }^{1}$ \\ Philipp Sewerin (1) ${ }^{1}$
}

To cite: Deike M, Brinks $\mathrm{R}$, Meller S, et al. Risk of psoriatic arthritis depending on age: analysis of data from 65 million people on statutory insurance in Germany. RMD Open 2021;7:e001975. doi:10.1136/ rmdopen-2021-001975

- Additional supplemental material is published online only. To view, please visit the journal online (http://dx.doi.org/10. 1136/rmdopen-2021-001975).

Received 25 September 2021 Accepted 16 November 2021

\section{Check for updates}

(C) Author(s) (or their employer(s)) 2021. Re-use permitted under CC BY-NC. No commercial re-use. See rights and permissions. Published by BMJ.

${ }^{1}$ Department and HillerResearch-Unit for Rheumatology, Heinrich Heine University Düsseldorf, Dusseldorf, Germany ${ }^{2}$ Department of Dermatology, Heinrich-Heine-Universitat Dusseldorf, Dusseldorf, Germany

Correspondence to Dr Philipp Sewerin; philipp.sewerin@med.uniduesseldorf.de

\section{ABSTRACT}

Objectives This study aims to provide a comprehensive analysis of the age-dependent risk of psoriatic arthritis (PsA). For this purpose, it focuses on the varying incidences within the different age groups.

Methods The data were collected as part of the morbidity-based risk adjustment of the statutory health insurance companies in Germany. This survey recorded the International Statistical Classification of Diseases and Related Health Problems (ICD)-coded diagnoses of 65 million German citizens. Our population-based study used these raw data to calculate the prevalence of PsA in the first step. Subsequently, we employed a new approach for the estimation of the age-specific and sex-specific incidence of PsA.

Results The age-specific and sex-specific incidence of PsA showed a continuous increase with rising age until it peaked slightly before the age of 60 and declined thereafter. The maximum value was higher in women (40 per 100000 py) than in men (30 per 100000 py). Furthermore, the incidence rate tends to climb over the survey period.

Conclusions The data sets identified an unexpected high incidence. A meta-analysis by Scotti et al and other recent population-based studies served as a reference for the comparison. The pattern of the age-specific incidence illustrated that the risk for PsA disease shows considerable variations depending on age.

\section{INTRODUCTION}

Psoriatic arthritis (PsA) is associated with a substantial burden of disease, even more than the purely cutaneous psoriasis ( $\mathrm{PsO}){ }^{1}$ Suffering from PsA can drastically restrict the patients' quality of life and thus ultimately impacts national healthcare policies. Numerous small-scale studies have examined the epidemiology of PsA in recent years. However, the validity of these studies is often reduced due to the modest sample sizes or limitations in study design. Therefore, experts have consistently asked for large

\section{Key messages}

Many studies already dealt with the epidemiology of psoriatic arthritis (PsA).

- However, due to different study designs and cohort sizes, the study results are characterised by a large heterogeneity.

- This study combines a large population-based trial and an age-specific and sex-specific presentation of the incidence of PsA that enables an assessment of disease risk depending on age.

- A new approach was used for the estimation of the incidence. In contrast to other studies, childhood and adolescence were also included in this study.

- The knowledge of the age-dependent risk of developing PsA could be of considerable importance for the early detection and secondary prevention of psoriasis patients.

population-based studies, which can provide reliable information on the distribution of PsA. ${ }^{2}$ The present datasets enable a comprehensive examination of the epidemiology of PsA in Germany. The analysis is based on the data of 65 million people on statutory insurance in Germany (covering $80 \%$ of the German population), which have been collected in the context of the morbiditybased risk adjustment. Furthermore, the results of this study will be placed in the context of other population-based studies, which represent the recent epidemiology of PsA at an international level. ${ }^{34}$

\section{METHODS}

The present data sets were collected as part of the morbidity-based risk adjustment by the statutory health insurance companies in Germany. ${ }^{5}$ The survey includes the International Statistical Classification of Diseases and Related Health Problems (ICD)-10-coded 
Table 1 Characteristics of the study population

\begin{tabular}{lllll}
\hline Year & $\mathbf{2 0 0 9}$ & $\mathbf{2 0 1 0}$ & $\mathbf{2 0 1 1}$ & $\mathbf{2 0 1 2}$ \\
\hline Population (n) & 64637752 & 63962071 & 64988016 & 65792296 \\
\hline Proportion of Women (\%) & 53.5 & 53.4 & 53.3 & 53.2 \\
Total number of psoriasis patients (n) & 1419537 & 1440807 & 1477333 & 1512769 \\
Total number of psoriatic arthritis patients (n) & 127334 & 137763 & 146463 & 156182 \\
\hline
\end{tabular}

Data collected for the morbidity-based risk adjustment of the statutory health insurance companies in Germany from 2009 to 2012.

diagnoses of all Germans with a statutory insurance between January 2009 and December 2012 (table 1). Only residents with private health insurance or without any insurance are excluded from this study. In contrast to previous reports this study covers adults as well as adolescents and children. The raw data were provided by the German Institute of Medical Documentation and Information.

The study opts for an age-specific representation of the incidence. This enables a differentiated view of the distribution of PsA in various phases of life. The absolute numbers of the morbidity-based risk adjustment have been employed for the calculation of the age-specific and sex- specific prevalences.

A second step estimates the incidence values for PsA in Germany. For this purpose, we used a formula introduced by Brinks et al, which requires the prevalence as well as the general mortality and the relative mortality associated with the disease. ${ }^{6} 7$ The values of the relative mortality were taken from a Danish study published by Ahlehoff et al, which was determined through a systematic literature search regarding disease-associated mortality of PsA. ${ }^{8}$ Furthermore, we calculated the age-standardised incidence to ensure comparability with other studies.

\section{RESULTS}

\section{Study population}

The study population comprised 64637752 individuals in 2009, increasing to a total of 65792296 individuals by the end of the survey period in 2012. The proportion of women slightly overweighted over the 4 years observed. The total number of patients suffering from PsA increased from approximately 127000 in 2009 to 156000 in 2012. The number of PsO cases paralleled this trend by rising from 1419537 cases in 2009 to a maximum of 1512,769 cases in 2012 (table 1).

\section{Age-specific and sex-specific prevalence of PsO}

The age-specific and sex-specific prevalence of $\mathrm{PsO}$ shows a steady increase until the sixth decade of life. After reaching the age of 60, a maximum of approximately 40 per 1000 is achieved. The prevalence of males slightly exceeds that of females. The values subsequently remain at high levels and drop only to a limited extent (figure 1).

\section{Age-specific and sex-specific prevalence of PsA}

A constant increase can be noted for the age-specific and sex-specific prevalence over the life course of men and women, until it reaches a plateau and declines afterwards. The prevalence plateaus at maximum of 5 per

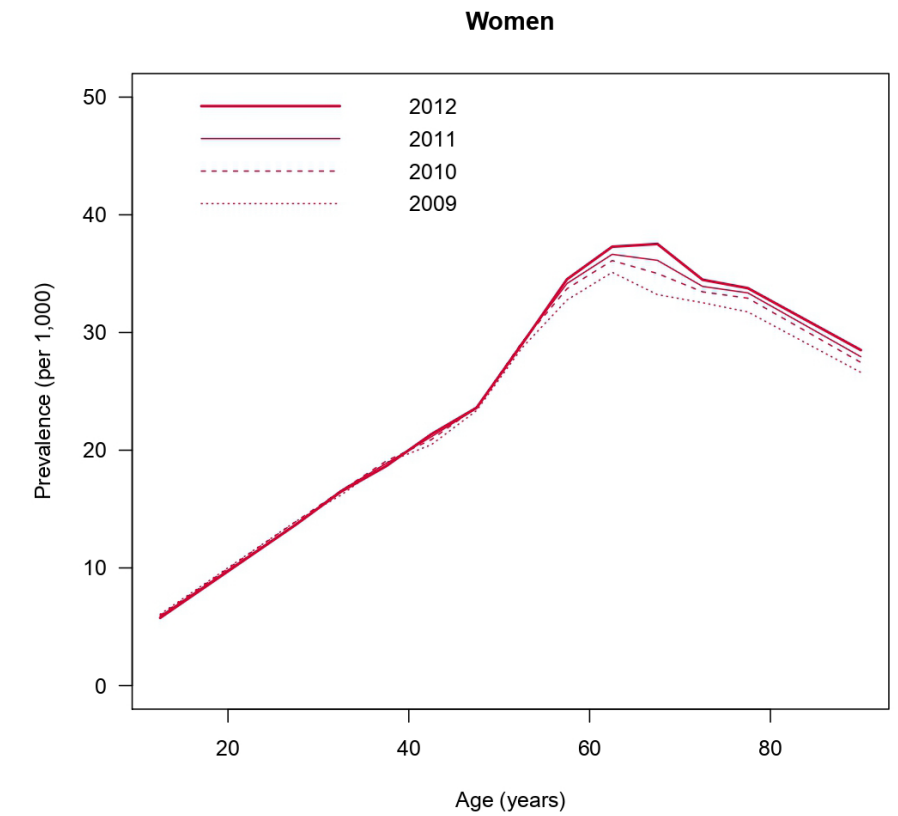

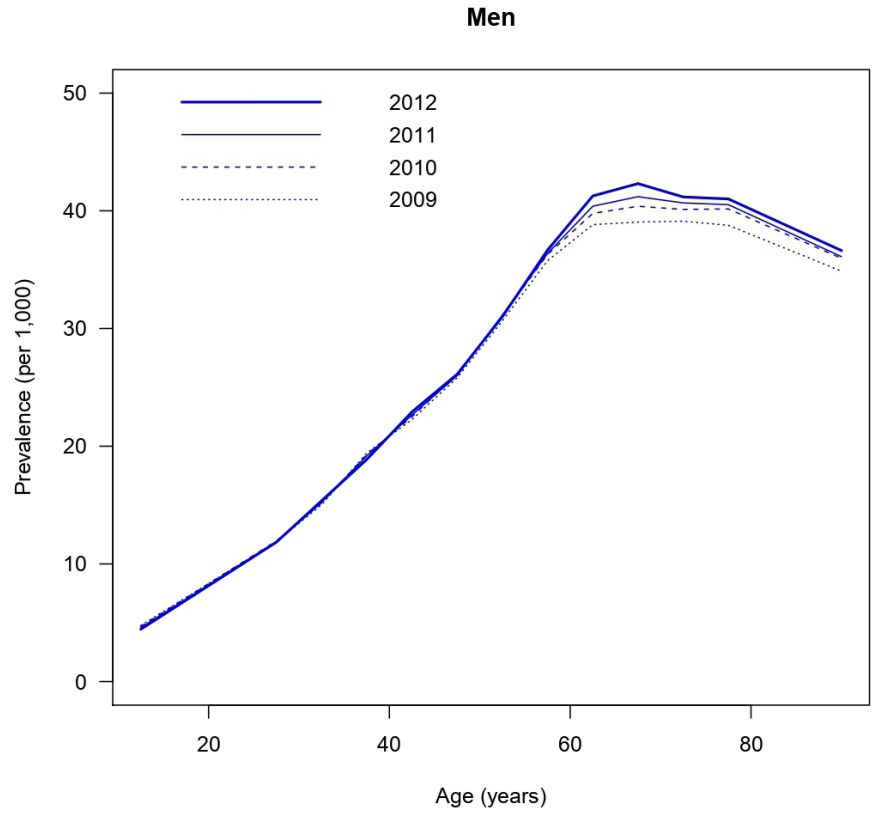

Figure 1 Age-specific and sex-specific prevalence of psoriasis (per 1000) in Germany between 2009 and 2012. 

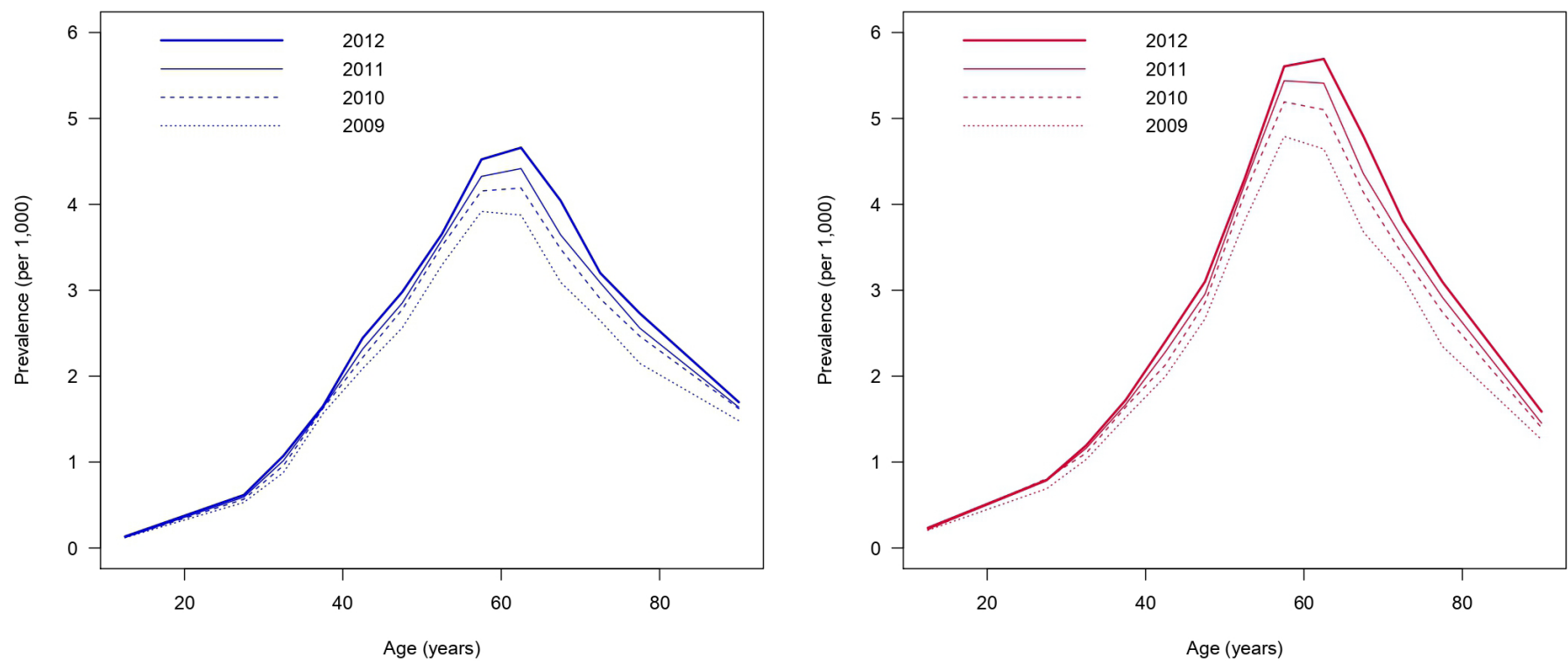

Figure 2 Age-specific and sex-specific prevalence of psoriatic arthritis (per 1000) in Germany between 2009 and 2012.

1000 for men and 6 per 1000 for women. There is a sharp decrease in the prevalence in both sexes after the age of 60 (figure 2).

\section{Age-specific and sex-specific incidence of PsA}

The incidence rose continuously over the patient's lifetimes until it peaked just before the age of 60 and rapidly declined thereafter. Most new cases occurred at the end of the fifth decade of life. The incidence assumes a maximum value of 30 per 100000 py in men and 40 per 100000 py in women (figure 3). In general, we observed an overall rise of the incidences during the study period.

\section{Age-standardised incidence of PsA}

The age-standardised incidence for PsA ranged from 15.46 per 100000 individuals (95\% CI 14.85 to 16.01 per 100000 py) to 17.31 per 100000 individuals $(95 \%$ CI 16.54 to 18.01 per 100000 py) in men (2009-2011). Similarly, the age-standardised incidence of women changed over this period from 17.19 per 100000 py (95\% CI 16.63 to 17.70 py) to 19.54 per 100000 py (95\% CI 18.84 to 20.25 per 100000 py).
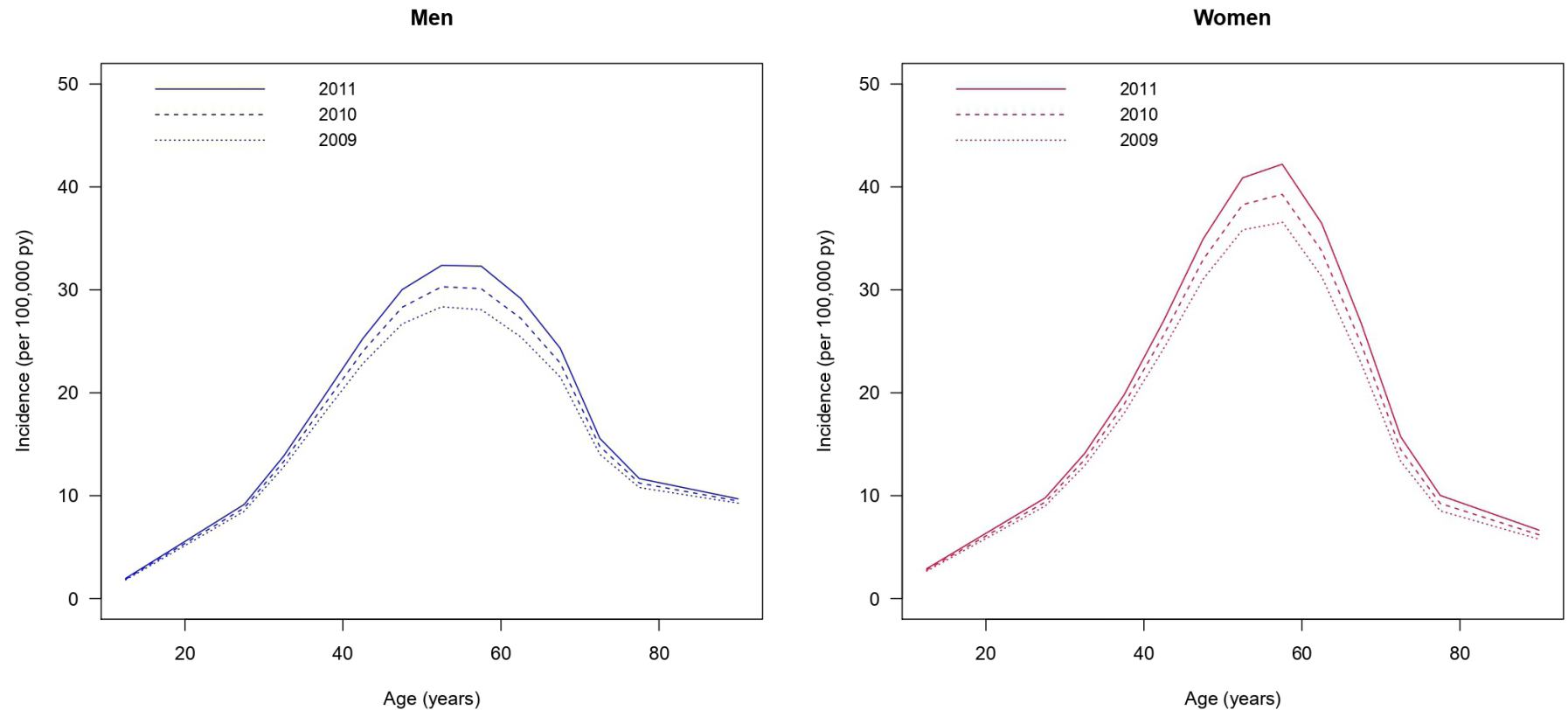

Figure 3 Age-specific and sex-specific incidence of psoriatic arthritis (per 100000 py) in Germany between 2009 and 2011. 


\section{DISCUSSION}

Deviating from other reports this study uses an agespecific and sex-specific description of the incidence. This allows a differentiated view of the frequencies of new cases according to life stage and gender. Current findings indicate that between $5 \%$ and $45 \%$ of $\mathrm{PsO}$ patients develop a PsA over the course of the disease. ${ }^{910}$ As shown in figure 3, the incidence rises continuously with increasing age. Most of the new cases occur between the ages of 50 and 59. Consequently, the risk of developing PsA is highest at this age.

As mentioned before, there is a direct correlation between the prevalence of plaque $\mathrm{PsO}$ and the occurrence of PsA. The higher the prevalence of $\mathrm{PsO}$ in an observed population, the higher the probability to develop PsA. ${ }^{2}$ Against this background, the drastic decrease in the incidence of PsA before reaching the age of 60 remains unaccounted for since the prevalence of plaque PsO fails to provide an adequate explanation (figure 1). Therefore, further interpretation of the varying incidence within the different age groups appears necessary.

As noted already, the incidence rises continuously over the 3-year survey period (figure 3). This trend has already been observed for the prevalence of these data sets and was previously reported and discussed by Sewerin et $a l^{10}$ (figure 2). Whereas other studies describe a stable course of the incidence of PsA. ${ }^{311}$ Possible explanatory approaches that may account for the differences are an improvement in diagnostic abilities, changed coding behaviour of ICD codes and an increased awareness of the disease.$^{12}$ However, a real increase in the incidence of PsA should be considered as well.

Unlike previous studies, a difference in the age-specific incidences between males and females was found in this cohort. ${ }^{2}$ While both sexes are affected by PsO to a similar degree, women appear to be more likely to develop PsA during the course of their disease. This fact can be especially observed in a postmenopausal age, so that a hormonal cause remains to be discussed.

With an average age-standardised incidence of approximately 17 per 100000 py, the values of this survey appear to be elevated compared with previous studies. A metaanalysis performed by Scotti et al pointed out the large heterogeneity in this field. Their analysis calculated a random effect pooled PsA incidence rate of 8.3 per 100 000 py. However, the incidences of the included studies ranged from 3.0 to 41.3 cases every 100000 py. $^{2}$ While there are limited data on the incidence of PsA in Germany for comparison, recent population-based studies confirm that the incidence is increased in the present study population. ${ }^{34}$

The large heterogeneity of data emphasised by Scotti et al can be explained by different study designs and cohorts. In contrast to other studies, this report stands out by combining a large population-based study and a new approach to incidence estimation. The present data sets offer a great potential for comprehensive analysis of the epidemiology of PsA in Germany. In order to constitute the population as a whole, this study included children and adolescents in addition to the adult population. This study design represents a unique feature in the field of PsA epidemiology.

However, the results of the report and the comparability with other studies should be viewed with caution due to different diagnostic criteria. While this study uses ICD-10-coded diagnoses to establish the diagnosis, other studies make use of the Classification Criteria for Psoriatic Arthritis (CASPAR criteria) or refer to a concurrent joint diagnosis of arthritis and $\mathrm{PsO} .^{2}$ Since any officially registered physician in Germany can make diagnoses of chronic conditions, general practitioners as well as specialists, the data are based on both primary and secondary care records. A classification as ascertained cases is required in the coding process. An estimation of completeness of the coded diagnoses has not been undertaken as the sensitivity of claims data is considered very good. ${ }^{4}$ Evidence for this assumption is provided by a paper that examines the accuracy of claims data in a similar data record of type 2 diabetes patients. ${ }^{13}$

The estimated incidence differs from the results published for these data sets in 2019. ${ }^{10}$ Due to missing values, only an approximate calculation could be performed at that time. Consequently, the approach now chosen is to be regarded as the more valid one, since the methodological weakness has been eliminated.

The difference in the observation period of prevalence and incidence arises from the new approach to incidence estimation. Further explanations can be found in the related paper by Brinks et al. ${ }^{14}$

As shown in figure 2, an impressive decrease in the age-specific and sex-specific prevalence of PsA was observed after the age of 60. A possible explanation for the change in the prevalence is the correlation between PsA and additional comorbidities, which coincide with an increased morbidity and mortality. ${ }^{15}$ The extent of the decrease also indicates that the incidence is not high enough to compensate the mortality excess of PsA patients. ${ }^{14}$ The data we have available does not allow to examine factors that drive excess mortality, for example, possible comorbidities. We can only describe that excess mortality exceeds the incidence, but unfortunately, we cannot provide reasons why this is the case.

Regardless of the observations made, it is important to stress that the total number of patients suffering from PsA is likely to be much higher than the numbers of identified cases. ${ }^{16}$ A correlation between joint complaints and $\mathrm{PsO}$ is not always taken into account.

However, the diagnosis of PsA is of considerable relevance to the prognosis and burden of disease. Accounting for the frequency and severity of PsA, the socioeconomic aspect should not be ignored either. For this reason, intensified early detection and secondary prophylaxis should be given greater priority in the care of $\mathrm{PsO}$ patients.

Acknowledgements We would like to express our gratitude to DIMDI (German Institute for Medical Documentation and Information) for preparing the data sets. 
Contributors All authors designed the evolution. MD, RB and PS performed the data analyses. MD and PS drafted the first version of the manuscript. All coauthors were involved in the critical interpretation of the results, discussed the findings together, critically reviewed the manuscript and approved its final version.

Funding The authors have not declared a specific grant for this research from any funding agency in the public, commercial or not-for-profit sectors.

Competing interests None declared.

Patient consent for publication Not applicable.

Provenance and peer review Not commissioned; externally peer reviewed.

Open access This is an open access article distributed in accordance with the Creative Commons Attribution Non Commercial (CC BY-NC 4.0) license, which permits others to distribute, remix, adapt, build upon this work non-commercially, and license their derivative works on different terms, provided the original work is properly cited, appropriate credit is given, any changes made indicated, and the use is non-commercial. See: http://creativecommons.org/licenses/by-nc/4.0/.

ORCID iD

Philipp Sewerin http://orcid.org/0000-0001-8465-6207

\section{REFERENCES}

1 Pariser D, Schenkel B, Carter C, et al. A multicenter, noninterventional study to evaluate patient-reported experiences of living with psoriasis. J Dermatolog Treat 2016;27:19-26.

2 Scotti L, Franchi M, Marchesoni A, et al. Prevalence and incidence of psoriatic arthritis: a systematic review and meta-analysis. Semin Arthritis Rheum 2018;48:28-34.

3 Karmacharya P, Crowson CS, Bekele D, et al. The epidemiology of psoriatic arthritis over five decades: a population-based study. Arthritis Rheumatol 2021;73:1878-85.

4 Pina Vegas L, Sbidian E, Penso L, et al. Epidemiologic study of patients with psoriatic arthritis in a real-world analysis: a cohort study of the French health insurance database. Rheumatology 2021;60:1243-51.
5 Bauhoff S, Fischer L, Göpffarth D, et al. Plan responses to Diagnosis-based payment: evidence from Germany's morbiditybased risk adjustment. J Health Econ 2017;56:397-413.

6 Brinks R, Landwehr S, Icks A, et al. Deriving age-specific incidence from prevalence with an ordinary differential equation. Stat Med 2013;32:2070-8.

7 Brinks R, Landwehr S. A new relation between prevalence and incidence of a chronic disease. Math Med Biol 2015;32:dqu024-35.

8 Ahlehoff $\mathrm{O}$, Gislason $\mathrm{GH}$, Charlot $\mathrm{M}$, et al. Psoriasis is associated with clinically significant cardiovascular risk: a Danish nationwide cohort study. J Intern Med 2011;270:147-57.

9 Ocampo D V, Gladman D. Psoriatic arthritis. F1000Res 2019;8. doi:10.12688/f1000research.19144.1. [Epub ahead of print: 20 Sep 2019].

10 Sewerin P, Brinks R, Schneider M, et al. Prevalence and incidence of psoriasis and psoriatic arthritis. Ann Rheum Dis 2019;78:286-7.

11 Eder L, Widdifield J, Rosen CF, et al. Trends in the prevalence and incidence of psoriasis and psoriatic arthritis in Ontario, Canada: a population-based study. Arthritis Care Res 2019;71:1084-91.

12 Wilson FC, Icen M, Crowson CS, et al. Time trends in epidemiology and characteristics of psoriatic arthritis over 3 decades: a population-based study. J Rheumatol 2009;36:361-7.

13 Brinks R, Tönnies T, Hoyer A. Impact of diagnostic accuracy on the estimation of excess mortality from incidence and prevalence: simulation study and application to diabetes in German men. F1000Res 2021;10:49.

14 Brinks R, Hoyer A, Landwehr S. Surveillance of the incidence of noncommunicable diseases (NCDS) with sparse resources: a simulation study using data from a national diabetes registry, Denmark, 19952004. PLoS One 2016;11:e0152046.

15 Edson-Heredia E, Zhu B, Lefevre C, et al. Prevalence and incidence rates of cardiovascular, autoimmune, and other diseases in patients with psoriatic or psoriatic arthritis: a retrospective study using clinical practice research Datalink. J Eur Acad Dermatol Venereol 2015;29:955-63.

16 Villani AP, Rouzaud M, Sevrain M, et al. Prevalence of undiagnosed psoriatic arthritis among psoriasis patients: systematic review and meta-analysis. J Am Acad Dermatol 2015;73:242-8. 